\title{
Water-dispersible and ferroelectric PEGylated barium titanate nanoparticles
}

\author{
M. Taheri, ${ }^{1,2,3, \text { a) }}$ B. Zanca, ${ }^{1}$ M. Dolgos, ${ }^{1}$ S. Bryant, ${ }^{3}$ and S. Trudel ${ }^{1,2, b)}$ \\ ${ }^{1)}$ Department of Chemistry, University of Calgary, 2500 University Drive NW, Calgary, AB, \\ Canada \\ ${ }^{2)}$ Institute for Quantum Science and Technology, University of Calgary, 2500 University Drive NW, Calgary, AB, \\ Canada \\ ${ }^{3)}$ Department of Chemical and Petroleum Engineering, University of Calgary, 2500 University Drive NW, Calgary, AB, \\ Canada
}

(Dated: 8 April 2021)

Dispersions of ferroelectric nanoparticles in aqueous medium can find promising applications in electro-optical, medical, and smart fluid technologies. In this report, we show the development of highly dispersed nano-sized ferroelectric barium titanate $\left(\mathrm{BaTiO}_{3}\right)$ powders with high dielectric constant prepared using a simple, one-step low temperature solution method. The surface of these tetragonal-structured nanoparticles were modified with polyethylene glycol as a stabilizer and dispersant. The crystal structure, morphology and dielectric constant of samples are discussed in detail. The colloidal stability and surface behavior of these PEGylated barium titanate nanoparticles are studied by means of $\zeta$-potential and dynamic light scattering measurements. We show changing the reaction conditions allows to tune the nanoparticle size. This research promotes a pathway to develop advanced ferroelectric nanomaterials with engineered properties in a simple way.

Keywords: $\mathrm{BaTiO}_{3}$, Dielectric Constant, Ferroelectrisity, Nanoparticle Dispersion, Polyethylene Glycol, Thermal Hysteresis, Surface Modification

\section{INTRODUCTION}

\section{INTRODUCTION}

Perovskite-type barium titanate $\left(\mathrm{BaTiO}_{3}\right)$ with four temperature-dependent crystalline forms (i.e. cubic, tetragonal, orthorhombic, and rhombohedral) is the most widely used ferroelectric (FE) material with applications in the electrical and electronic industries, mainly as multilayer ceramic capacitors, piezoelectric sensors and dielectrics. ${ }^{1}$ The tetragonal phase (space group $P 4 / \mathrm{mmm}$, see Fig. S1) supports a permanent electric polarization and a high dielectric constant $\left(\varepsilon_{\mathrm{r}}^{\prime} \approx 5000-15000\right)$ up to the FE Curie-Weiss temperature $(\approx$ $130^{\circ} \mathrm{C}$ ); at higher temperatures it converts to a fully symmetric cubic structure and becomes paraelectric. In this symmetric phase, $\mathrm{BaTiO}_{3}$ shows a temporary polarization under an application of electric field. It is well known that the tetragonal phase of $\mathrm{BaTiO}_{3}$ switches to the cubic non-ferroelectric phase at room temperature below a critical size. Reported critical sizes vary from as small as a few $\mathrm{nm}^{2,3}$ to $c a$. $100 \mathrm{~nm}^{4}$

Stable FE nanoparticle suspensions are required for various proposed applications including drug delivery, imaging, solution-based ceramics and coatings fabrication, and pigments. $^{5-7}$ Recent efforts have focused on the dispersion of ferroelectric $\mathrm{BaTiO}_{3}$ nanopowders in either aqueous or organic media. ${ }^{5,7-9}$ Since these ceramic particles boast superior ferroelectric/pizoelectric/pyroelectric properties, are competitively low-cost, non-toxic and biocompatible, they present great potential for use in electrorheological fluids and biomed-

\footnotetext{
a)Electronic mail: maryam.taheri2@ucalgary.ca

b)Electronic mail: trudels@ucalgary.ca
}

ical imaging applications. ${ }^{7,10}$ Several synthesis methods for the preparation of $\mathrm{BaTiO}_{3}$ nanoparticles have been proposed, including high temperature solid-state reaction, ${ }^{11}$ sol-gel, ${ }^{12}$ co-precipitation, ${ }^{13}$ and hydrothermal ${ }^{14}$ approaches. However, most of these methods are not conducive to making uniform well-dispersed $\mathrm{BaTiO}_{3}$ nanoparticles. Bare $\mathrm{BaTiO}_{3}$ particles are not thermodynamically stable in water/organic solvents, specifically in acidic aqueous solutions where $\mathrm{Ba}^{2+}$ ions are leached out from the surface of $\mathrm{BaTiO}_{3}$ molecules. Therefore adding surfactants, polymers or polyelectrolytes are needed to make them dispersible in the liquid phase. ${ }^{15}$

We chose poly(ethylene glycol) (PEG) to stabilize aqueousdispersed $\mathrm{BaTiO}_{3}$ nanoparticles based on its high solubility in water, biocompatibility and eco-friendliness, and its well-documented ability to solubilize metal and metal oxide nanoparticles. ${ }^{16,17}$ Although PEG has been widely used in the synthesis of nanoparticles to promote stability control and nanoparticle size, its use to disperse $\mathrm{BaTiO}_{3}$ nanoparticles is limited. ${ }^{18,19}$ Moreover, modification with PEG is suggested to improve the dielectric properties of ceramic particles. ${ }^{18,20}$

In this work we present the preparation and characterization of PEGylated $\mathrm{BaTiO}_{3}$ nanoparticles prepared using a low-temperature one-pot synthesis. We synthesise tetragonal $\mathrm{BaTiO}_{3}$-PEG core-shell nanoparticles in the 40-70 nm diameter range, with high water dispersibility and large dielectric constant. We show how we can modify the synthetic parameters to control the particle size, and their corresponding stability in water. Furthermore, we report the temperaturedependence dielectric constant of prepared samples. This method is fast, simple, and cost-effective, attributes that are necessary for large-scale industrial deployment. 


\section{EXPERIMENTAL METHODS}

\section{A. Nanoparticle Synthesis}

PEGylated $\mathrm{BaTiO}_{3}$ nanoparticles were prepared using a one-step protocol. All reactions were carried out under stirring and inert nitrogen atmosphere while the temperature was monitored and controlled with a digital PID controller. All syntheses are fully detailed in the ESI. In a representative synthesis to prepare sample BT-1, we dissolved $\mathrm{Ba}(\mathrm{acac})_{2} \cdot \mathrm{xH}_{2} \mathrm{O}$ (355 mg, $1 \mathrm{mmol})$ and $(\mathrm{O}-i-\mathrm{Pr})_{2} \mathrm{Ti}(\mathrm{acac})_{2}(273 \mathrm{mg}, 1 \mathrm{mmol})$ precursors in $3 \mathrm{~mL}$ of $\mathrm{PEG}_{400}$ in a round-bottom flask under nitrogen atmosphere, and let the solution stir for $30 \mathrm{~min}$. We then added aqueous $\mathrm{KOH}(6 \mathrm{~mL}, 1.5 \mathrm{M})$ to the mixture to adjust the $\mathrm{pH}$ of the solution to $c a$. 14, which was found to be crucial for the nucleation of $\mathrm{BaTiO}_{3}$ particles. ${ }^{21}$ Immediately after, we increased the reaction temperature to reflux (ca. $100 \pm 5{ }^{\circ} \mathrm{C}$ ), and allowed the reaction to reflux for $2 \mathrm{hrs}$. The color of solution gradually changed from orange/brown to white. After $2 \mathrm{hrs}$ of reflux, we added $6 \mathrm{~mL}$ of distilled water to the mixture and maintained it at $100 \pm 5{ }^{\circ} \mathrm{C}$ for an additional $2 \mathrm{hrs}$. We then opened the system to air and let the reaction cool down to room temperature. White precipitates were collected by washing and centrifugation (6000 rpm for $10 \mathrm{~min}$ ) two times with ethanol, followed by formic acid (1 M). Carbonate impurities were removed by washing the product with diluted $(0.5 \mathrm{w} / \mathrm{w} \%)$ acetic acid. Finally, the nanoparticles were dried at $60^{\circ} \mathrm{C}$ in a vacuum oven overnight.

In order to study the effect of reaction conditions on particle size and dispersibility, we modified the ratio of the metal precursors ( $\mathrm{Ti}$ and $\mathrm{Ba}$ molar ratio), $\mathrm{KOH}$ and $\mathrm{PEG}$ for samples BT-1 to BT-5 and summarized in Table I. We prepared sample BT-0 under similar conditions to BT-1, without adding PEG, to provide a reference sample with no surface modification.

\section{B. Physical Characterization}

Powder X-ray diffraction (PXRD). Structural characterization was carried out using a Bruker D8 ECO Advance powder diffractometer $(\mathrm{Cu} \mathrm{K} \alpha, \lambda=1.5406 \AA$, $25 \mathrm{~mA} \times 40$ $\mathrm{kV}$ power, in the range of $2 \theta=15-75^{\circ}$, and increment of $0.02^{\circ}$ ). Profile refinement of XRD patterns was performed with the Fullprof software. ${ }^{22}$ Crystallite size ( $\left.D_{\mathrm{XRD}}\right)$ was estimated using the Scherrer equation (see SI). ${ }^{23}$

Electron microscopy. A FEI Quanta 250 FEG fieldemission scanning electron microscope (SEM) and $120 \mathrm{kV}$ Hitachi H7650 transmission electron microscope (TEM) were used to image the nanoparticles. Powders were mounted on SEM sample stubs using double-sided carbon adhesive tape. A drop of particles dispersed in ethanol was allowed to dry on a TEM carbon-coated copper grid. Micrographs were analysed using Image J software. ${ }^{24}$

Fourier-transform infrared (FTIR) spectroscopy. FTIR spectra were recorded with an Agilent Cary 630 spectrum with a diamond attenuated total reflectance (ATR) probe, and reported as transmittance.
Dynamic light scattering (DLS) and $\zeta$ potentials. DLS data and $\zeta$-potential of dispersed $\mathrm{BaTiO}_{3}$ nanoparticles were analysed using a Malvern Zetasizer Nano ZS DLS system. For each time-point, three sequential measurements were made at room temperature to estimate the size, surface charge and dispersiblity of $100 \mathrm{ppm}$ dried $\mathrm{BaTiO}_{3}$-PEG nanoparticles dispersed in DI water.

Ferroelectric properties. In order to study the ferroelectrisity of sample BT-1, a pellet was fabricated by mixing powder with a solution of $3 \mathrm{wt} \%$ polyvinyl butyral in ethanol in a ratio of 10 drops per gram. The mixture was pressed into the cylindrical pellet using a Carver uniaxial press and a 13-mm stainless steel die. Three metric tons of pressure was applied and held for 2 min to ensure the integrity of the pellet. In order to achieve high relative densities while minimizing grain growth, pellet was sintered in an alumina boat (CoorsTek) using a two-step temperature profile. ${ }^{25,26}$ The pellet was first heated to $1300^{\circ} \mathrm{C}$ at a rate of $5^{\circ} \mathrm{C} \mathrm{min}-1$, holding at that temperature for $1 \mathrm{~min}$, then cooling to $950{ }^{\circ} \mathrm{C}$ at a rate of $30{ }^{\circ} \mathrm{C} \mathrm{min}{ }^{-1}$; this temperature was maintained for $10 \mathrm{hrs}$ and then cooled to room temperature at a rate of $5{ }^{\circ} \mathrm{C} \mathrm{min}^{-1}$.

The density $\rho_{\exp }$ of each pellet was measured with a Mettler Toledo analytical balance equipped with an Archimedes kit (with the accuracy of $\pm 0.01 \mathrm{~g} \mathrm{~cm}^{-3}$ ). The relative density $\rho_{r}$ of the pellet was calculated as $\rho_{\mathrm{r}}=100 \%\left(\rho_{\mathrm{exp}} \cdot \rho_{\text {theo }}^{-1}\right)$, where $\rho_{\text {theo }}$ is the theoretical crystallographic density obtained from XRD pattern refinements. To perform dielectric constant measurement, pellets were polished on all sides using 800, 1200, and 4000 grit silicon-carbide polishing films (Stuers). Then, silver electrodes were painted on both sides of the pellet using a silver paint (SPI Supplies) and sintered at $550{ }^{\circ} \mathrm{C}$ for $15 \mathrm{~min}$ with a heating/cooling ramp rate of $5^{\circ} \mathrm{C} \mathrm{min}^{-1}$. The dielectric properties were measured with a Solartron 1260 and 1296 coupled with a Probostat high-temperature sample stage inserted into a vertical tube furnace (Carbolite-Gero, VTF). The sample was heated/cooled at a rate of $1{ }^{\circ} \mathrm{C} \mathrm{min}^{-1}$ from room temperature $\left(\approx 20-22^{\circ} \mathrm{C}\right.$ ) to $200{ }^{\circ} \mathrm{C}$. Data was collected on both the heating and cooling cycles, every $5{ }^{\circ} \mathrm{C}$ until near the transition temperature $\left(T_{\mathrm{C}} \approx 115\right)$, then every $1{ }^{\circ} \mathrm{C}$ until after $T_{\mathrm{C}}$, then every $10^{\circ} \mathrm{C}$. The tested frequencies ranged from $1 \mathrm{~Hz}$ to $100 \mathrm{kHz}$ with 5 points per decade.

\section{RESULTS AND DISCUSSION}

\section{A. Structural Characterization and Size Control}

PXRD of the collected powders without a washing step indicated the major product of the reaction is $\mathrm{BaTiO}_{3}$. However, the presence of undesired $\mathrm{BaCO}_{3}$ was detected (Fig. S2a). This impurity is easily removed by washing the powders with diluted acetic acid $(0.5 \% \mathrm{w} / \mathrm{w})$, which is known to dissolve $\mathrm{BaCO}_{3} .{ }^{27}$ After washing, all PXRD patterns show a singlephase product consisting of only $\mathrm{BaTiO}_{3}$ (see Fig. S2b).

The size of the crystalline $\mathrm{BaTiO}_{3}$ cores $\left(D_{\mathrm{XRD}}\right)$ were estimated from Scherrer's formula ${ }^{23}$ through fitting of the (110) peak (see Fig. S3 and equations S1-S2). A size of $\sim 40 \mathrm{~nm}$ is determined for BT-1; $D_{\mathrm{XRD}}$ decreases from this reference 
point through increasing concentration of $\mathrm{Ba}^{+2}$, PEG content, or KOH molarity (See Table I).

Fig. 1 shows the room-temperature PXRD pattern of sample BT-1 . The observation of two closely related (002) and (200) reflections near $2 \theta \approx 45^{\circ}$ suggests the formation of a tetragonal structure with the space group $P 4 / \mathrm{mmm}$, whereas a single (200) peak would be observed for cubic $\mathrm{BaTiO}_{3}$ (space group: $P m 3 m$ ). Rietveld XRD refinement gives lattice parameters of $a=b=4.03 \AA$ and $c=4.05 \AA$ for sample BT-1, which are slightly larger than lattice parameters' of bulk $\mathrm{BaTiO}_{3}(a=$ $b=4.03 \AA$ and $c=4.05$ and in good agreement with published values of 4.03 to $4.05 \AA$ in $\mathrm{BaTiO}_{3}$ nanoparticles. ${ }^{28,29}$ The $c / a$ ratio of 1.005 suggests the structure is moderate tetragonal, while strong tetragonality value is reported about $1.010 .^{30} \mathrm{Ta}-$ ble II summarizes the refined lattice parameters and selected bond distances. The data shows that the lattice parameters of samples with smaller particle sizes slightly increase, indicating smaller tetragonality value. Similarly, internal bond distances increase with this lattice expansion. Smaller nanoparticles can have larger unit cell, owing to various factors including defects, surface tension or symmetry reduction. A lattice expansion concurrent with size reduction has frequently been reported for $\mathrm{BaTiO}_{3}$ nanoparticles; this trend converts the tetragonal phase to the cubic phase structure in very small particles. ${ }^{31,32}$

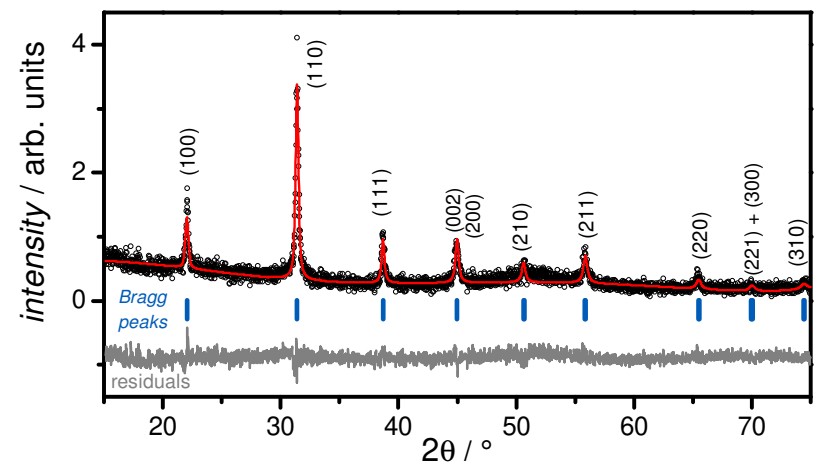

FIG. 1. Refined room temperature XRD pattern for BT-1. Scatter points are the measured data and are superimposed with the fit; the residual is plotted below. The position of the Bragg reflections is indicated by small vertical bars.

The morphology of PEGylated $\mathrm{BaTiO}_{3}$ nanoparticles was analyzed using SEM and TEM. As can be seen in the SEM micrographs (Fig. S4), BT-1 particles are uniformly quasispherical with rough surfaces ascribed to the PEG adsorbed on the nanoparticles' surfaces. The average particle size decreases from $\approx 70 \mathrm{~nm}$ for BT-1 to $\approx 40-48 \mathrm{~nm}$ in samples BT-2 to BT-5, with no change in the shape of particles. The formation of $\mathrm{BaTiO}_{3}-\mathrm{PEG}$ core-shell structures in all samples were observed in the TEM micrographs (Fig. 2) with an average shell thickness of $c a .5-7 \mathrm{~nm}$ in the dry state. The average particle size observed through TEM are in good agreement with data obtained from SEM. All average particle sizes are compiled in Table I. The differences between $D_{\text {XRD }}$ and $D_{\text {SEM }}$ or $D_{\text {TEM }}$ are consistent with the presence of a 7-nm PEG shell.

According to the literature, a dissolution-precipitation mechanism is responsible for $\mathrm{BaTiO}_{3}$ nanoparticle formation in this work, involving a reaction between $\mathrm{Ti}(\mathrm{OH})_{x}^{4-x}$ hydroxytitanium complexes and barium ions, resulting in the precipitation of $\mathrm{BaTiO}_{3}$ particles. ${ }^{21,33}$ Taking BT-1 as a reference point, a higher concentration of $\mathrm{Ba}^{2+}$ ions in BT-2 decreases the average particle size. This is ascribed to an increase of the nucleation rate; more seeds being presents implies the precursor is redistributed on more particles, leading to an average lower size. Similarly, increasing the amount of PEG yields smaller particles. The average particle size with no PEG present (BT-0) was obtained $\approx 110 \mathrm{~nm}$; it decreased to $\approx$ $60 \mathrm{~nm}$ in BT-1 and further to $\approx 40 \mathrm{~nm}$ for BT-3. We infer the polymers adsorbed on the surface of growing $\mathrm{BaTiO}_{3}$ particles hinders grain growth, resulting in the smaller nanoparticles. A similar behavior has been seen in poly(vinylpyrrolidone)coated $\mathrm{BaTiO}_{3}$ nanoparticles synthesized by Li et al.,${ }^{21}$ where the particle size decreased upon adding more PVP polymer. Finally, higher $\mathrm{KOH}$ concentration also accelerates nucleation rate, creating smaller particles (see samples BT-1, BT-4, and BT-5).

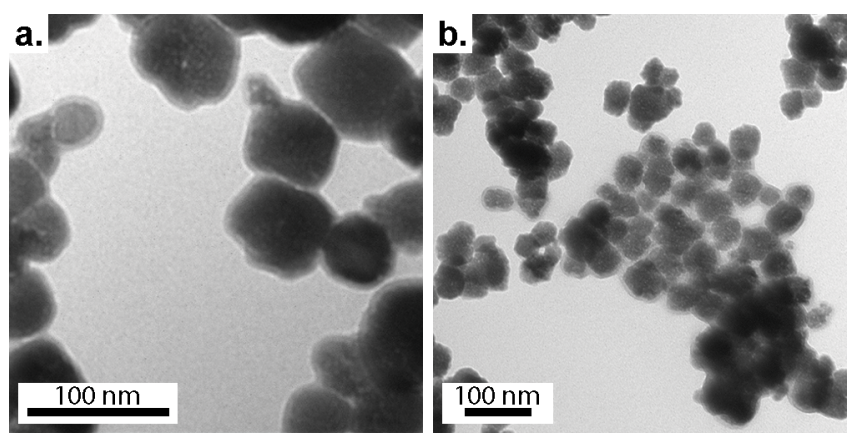

FIG. 2. TEM micrographs of samples BT-1 (a) and BT-3 (b), showing core-shell structures, where the lighter shell is the PEG polymer coating.

\section{B. Nanoparticle Coating and Water Dispersibility.}

The presence of the polymer on the nanoparticles' surface was confirmed by ATR-FTIR spectroscopy. Fig. 3 represents the FTIR spectra of PEGylated-BaTiO 3 nanoparticles (BT-1, BT-4 and BT-5), as well as neat PEG 400 . Several peaks are attributed to the presence of PEG: the $\mathrm{C}-\mathrm{H}$ out-of-plane bending vibrations (near $950 \mathrm{~cm}^{-1}$ ); in-plane $\mathrm{C}-\mathrm{H}$ and $\mathrm{O}-\mathrm{H}$ as well as C-O-C stretching vibrations (features between 990 to $1250 \mathrm{~cm}^{-1}$ ); $\mathrm{C}-\mathrm{H}$ bending vibrations (near $1450 \mathrm{~cm}^{-1}$ ), and CH symmetric and asymmetric stretches (bands around 2900 and $2850 \mathrm{~cm}^{-1}$ ), respectively. ${ }^{17}$ As expected, the bands assigned to $\mathrm{PEG}_{400}$ are present in the PEGylated samples (highlighted in yellow), while they are absent in the spectrum of the bare BT-0 nanoparticles. The broad O-H stretching modes of surface-adsorbed water observed around $3500 \mathrm{~cm}^{-1}$ and the deformation mode of absorbed $\mathrm{H}_{2} \mathrm{O}$ molecules, assigned to the bending vibration around $1600 \mathrm{~cm}^{-1}$ were features that have been reported in $\mathrm{BaTiO}_{3}$ FTIR spectrum ${ }^{34}$ which are highlighted in blue in all $\mathrm{BaTiO}_{3}$ samples. 


\begin{tabular}{lcccccr}
\multicolumn{2}{l}{ Sample $[\mathrm{Ba}] /[\mathrm{Ti}]$} & relative $[\mathrm{PEG}]$ & $\begin{array}{c}{[\mathrm{KOH}]} \\
(\mathrm{M})\end{array}$ & $\begin{array}{c}D_{\mathrm{XRD}} \\
(\mathrm{nm})\end{array}$ & $\begin{array}{c}D_{\mathrm{SEM}} \\
(\mathrm{nm})\end{array}$ & $\begin{array}{r}D_{\mathrm{TEM}} \\
(\mathrm{nm})\end{array}$ \\
\hline BT-1 & 1 & 1 & 1.5 & 39.8 & $69.9 \pm 9.5$ & $57.6 \pm 10.3$ \\
BT-2 & 2 & 1 & 1.5 & 32.3 & $47.9 \pm 7.7$ & $40.4 \pm 7.9$ \\
BT-3 & 1 & 2 & 1.5 & 31.2 & $43.9 \pm 6.3$ & $40.2 \pm 5.4$ \\
BT-4 & 1 & 1 & 1.6 & 33.6 & $39.8 \pm 6.4$ & $41.8 \pm 6.3$ \\
BT-5 & 1 & 1 & 1.7 & 29.9 & $43.4 \pm 7.2$ & $37.4 \pm 4.8$ \\
\hline
\end{tabular}

TABLE I. Reaction conditions and impact on $\mathrm{BaTiO}_{3}$ nanoparticle sizes determined from XRD, SEM, and TEM data

\begin{tabular}{lcccccr}
\hline Sample & $\begin{array}{c}a=b \\
(\AA)\end{array}$ & $\begin{array}{c}c \\
(\AA)\end{array}$ & $c / a$ & $\begin{array}{c}\mathrm{d}_{B a-T i} \\
(\AA)\end{array}$ & $\begin{array}{c}\mathrm{d}_{T i-O 1}(\AA) \\
(\AA)\end{array}$ & $\begin{array}{r}\mathrm{d}_{T i-O 2} \\
(\AA)\end{array}$ \\
\hline BT-1 & $4.03(1)$ & $4.05(2)$ & 1.005 & $3.49(8)$ & $2.02(6)$ & $2.01(6)$ \\
BT-2 & $4.05(7)$ & $4.07(5)$ & 1.004 & $3.51(9)$ & $2.03(8)$ & $2.02(9)$ \\
BT-3 & $4.04(9)$ & $4.06(4)$ & 1.004 & $3.51(1)$ & $2.03(2)$ & $2.02(5)$ \\
BT-4 & $4.04(5)$ & $4.06(4)$ & 1.004 & $3.50(8)$ & $2.03(2)$ & $2.02(3)$ \\
BT-5 & $4.04(6)$ & $4.06(5)$ & 1.004 & $3.50(9)$ & $2.03(3)$ & $2.02(2)$ \\
\hline
\end{tabular}

TABLE II. Lattice parameters $(a, b, c)$ and internal atomic lengths, obtained from the refined XRD data.

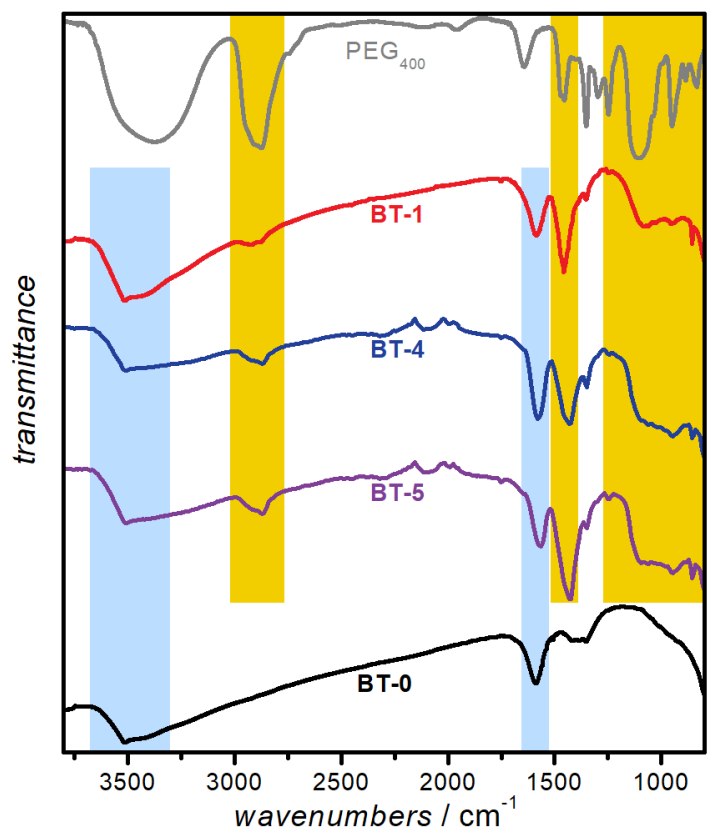

FIG. 3. FT-IR transmittance spectra of (a) BT-0, BT-1, BT-4, BT$\mathbf{5}$ and $\mathrm{PEG}_{400}$. Common peaks attributed to the PEG coverage are highlighted in yellow and the peaks assigned to $\mathrm{BaTiO}_{3}$ are highlighted in blue.

DLS and $\zeta$-potential measurements is a combination of techniques to determine the size distribution of small particles in suspension, and their surface charge. As suspended nanoparticles undergo Brownian motion, they scatter an incident laser beam in all directions; the scattering intensity fluctuates over time due constructive and destructive interference. An analysis of this scattered light yields the diffusion coefficient of the scattering species; the hydrodynamic radius is calculated through the Stokes-Einstein equation. The particles aggregation in the solution can be recorded by DLS measurements of a sample over time whether the hydrodynamic radius of the particle increases or not. ${ }^{35,36}$ The $\zeta$-potential, which depends on the surface charge, is a useful parameter to determine the stability of nanoparticles in a suspension. Nanoparticles with $\zeta$-potential magnitude of 20 to $30 \mathrm{mV}$ typically show the highest degrees of stability. ${ }^{36}$

Fig. S5a illustrates the images of $100 \mathrm{ppm}$ solution of $\mathrm{BaTiO}_{3}$ nanoparticles (in DI water, $\mathrm{pH} \approx 7$ ) after $10 \mathrm{~min}$ sonication with an ultrasonic homogenizer $(\approx 4 \mathrm{~kJ}$ energy); Fig. S5b shows the same solutions 24 hrs later, with no disturbing. This visual test shows that the BT-0 solution is more whitish-milky with phase separation, and that the particles clearly precipitate after $24 \mathrm{hrs}$ (Fig. S5b), highlighting the importance of the PEG coating for colloidal stability. The large hydrodynamic size $(\approx 300 \mathrm{~nm}$, see Fig. 4$)$ indicates agglomeration and is the likely reason for the low stability of these uncoated nanoparticles in the solution.

We examined the nanoparticle's $\zeta$-potential and hydrodynamic diameters $\left(D_{D L S}\right)$ (Fig. 4$)$ to better assess their stability in water. All particles show zeta potentials in -31 to -22 $\mathrm{mV}$ range; this is indicative of stable nanoparticles in this medium. ${ }^{36}$ Sample BT-1 shows the highest $\zeta$-potential among all samples $(-30.6 \pm 0.5 \mathrm{mV})$. Their hydrodynamic diameters is around $150-250 \mathrm{~nm}$; the trend generally follows the trends observed in Table I, although the sizes are larger as they represent the hydrodynamic radius, not only the inorganic core size.

In order to better understand these nanoparticles' stability, the $\zeta$-potential of $100 \mathrm{ppm}$ BT-1 nanoparticles in DI water measured over a $24-\mathrm{hr}$ period (Fig. 4b). The measured $\zeta$ potentials show only a slight variation, oscillating around an average value of $-30 \pm 0.5 \mathrm{mV}$, indicating good stability for dispersion of these nanoparticles. Moreover, the negative sur- 
face charge of particles due to the electrostatic interaction of surface-modified particles in the aqueous medium might explain the agglomeration delay and enhanced particles' distribution in the solvent. In general non-ionic PEG polymer acts as a dispersant and prevents agglomeration by creating steric repulsion between particles covered with a hydrated layer in DI water, ${ }^{16}$ therefore, nanoparticles coated with PEG have smaller hydrodynamic particle sizes.

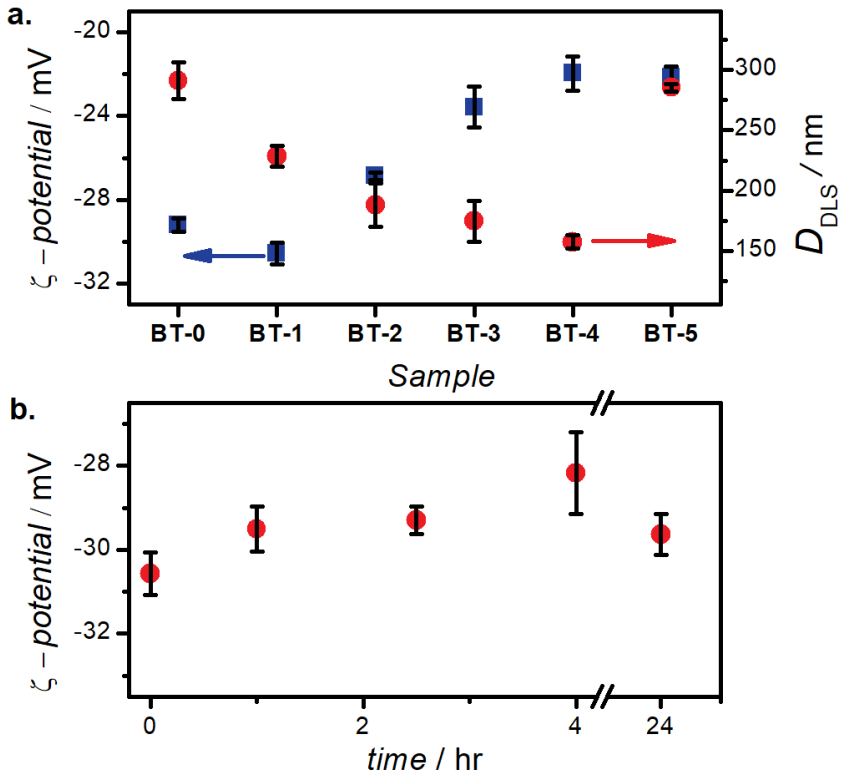

FIG. 4. a. $\zeta$-potential and hydrodynamic diameter of all $\mathrm{BaTiO}_{3}$ samples, and b. time variation of $\zeta$-potentials of BT-1 nanoparticles over 24 hrs, indicating stability.

\section{Ferroelectric Properties}

The relative dielectric constant $\left(\varepsilon_{r}^{\prime}\right)$ of BT-1 pellet are measured as a function of temperature (Fig. 5); these measurements are conducted on a pellet with a relative density of $86.7 \%$ at a frequency of $10 \mathrm{kHz}$ during heating and cooling cycles. The observed dieletric behaviour is typical of ferroelectrics, $\varepsilon_{r}^{\prime}$ increases with temperature to reach the maximum at the ferroeletric-to-paraelectric (FE-PE) transition temperature $\left(\mathrm{T}_{C}\right)$, and then decreases. The observed $\mathrm{T}_{C}$ of $\approx 130{ }^{\circ} \mathrm{C}$ is in close agreement with the reported phase transition for $\mathrm{BaTiO}_{3}$ ceramics. ${ }^{1}$ The $\varepsilon_{r}^{\prime}$ value of $\approx 2900$ at room temperature and $\varepsilon_{r}^{\prime}(\max )$ of 6500 at the $\mathrm{T}_{C}$ indicate that BT-1 is a strong ferroelectric compound, owing to its tetragonal structure. Above this transition temperature (paraelectric region), $\varepsilon_{r}^{\prime}$ follows the Curie-Weiss law,

$$
\varepsilon_{r}^{\prime}=\frac{A}{T-T_{C}}
$$

where $A$ is a constant (determined from the slope of $1 / \varepsilon_{r}^{\prime}$ versus $\left(T-T_{C}\right)$ (see Fig. 5b). The determined Curie-Weiss constant of $A \approx 14.7 \times 10^{4}$ is in the same range of reported values in literature. ${ }^{2}$ The obtained heating and cooling cycles show a thermal hysteresis at $\mathrm{T}_{C}$ (difference between $\mathrm{T}_{C}$ (heating) and $\mathrm{T}_{C}$ (cooling)), indicating that the ferroelectric-paraelectric anomaly is first-order. ${ }^{37,38}$ The transition temperature detected on heating $\left(\mathrm{T}_{C}=135^{\circ} \mathrm{C}\right)$ is usually larger than the transition temperature observed on cooling $\left(\mathrm{T}_{C}=125{ }^{\circ} \mathrm{C}\right)$. The thermal hysteresis of $10{ }^{\circ} \mathrm{C}$ at the FE-PE transition temperature of $\mathrm{BaTiO}_{3}$ has already been reported by Baskaran et al., ${ }^{37}$ although the hysteresis is often reported to be less than $5^{\circ} \mathrm{C} .2,38$

The temperature dependence of $\varepsilon_{r}^{\prime}$ and loss tangent $(\tan \delta$ ) during cooling cycle, at different frequencies, are shwpn in Fig. 5c-d. We observe that $\varepsilon_{r}^{\prime}$ and $\tan \delta$ decrease, and that the Curie-Weiss transition temperature slightly shifts to a lower temperature with increasing frequency. The highest value of $\varepsilon_{r}^{\prime}$ at $1 \mathrm{~Hz}$ is 11000 at $\mathrm{T}_{C}=126^{\circ} \mathrm{C}$. The lowest value of 5950 at the transition temperature is also recorded for the frequency of $100 \mathrm{kHz}$. This large values of dielectric constant in nanoparticles can be attributed to the existence of uniform grains, easier domain walls movement, surface effect and also higher local space charge field due to the large surface area. ${ }^{39}$

\section{v. CONCLUSIONS}

In summary, easily water-dispersed $\mathrm{BaTiO}_{3}$-PEG coreshell particles with an average particle size of $60 \mathrm{~nm}$ and a tetragonality value of 1.005 were prepared using a simple and fast low-temperature synthesis method. The impact of experimental conditions on particle size and crystal structure were studied, confirming lattice expansion and tetragonality reduction in smaller particles. Surface bonding between $\mathrm{BaTiO}_{3}$ particles and PEG molecules were studied using FT-IR. THe measured $\zeta$-potential of $\approx-30 \mathrm{mV}$ is indicative of good stability and redispersibility of these surface-modified particles. Furthermore, the large values of dielectric constant $(\approx 6000$ $11000)$ at the transition temperature of $\mathrm{T}_{C}=125-135^{\circ} \mathrm{C}$ confirm the strong ferroelectricity in this sample. These findings provide a simple solution to nanoparticle aggregation, thereby improving the stability of ferroelectric dispersion.

\section{CONFLICTS OF INTEREST}

There are no conflicts to declare.

\section{ACKNOWLEDGEMENTS}

We thank the Natural Sciences and Engineering Research Council of Canada (NSERC; Discovery Grant, RTI, and PDF), the Canada Excellence Research Chair (CERC) program, and the University of Calgary's Global Research Initiative in Sustainable Low Carbon Unconventional Resources funded by the Canada First Research Excellence Fund (CFREF) for supporting this research. We thank Dr. Berton for performing thermal analysis. 

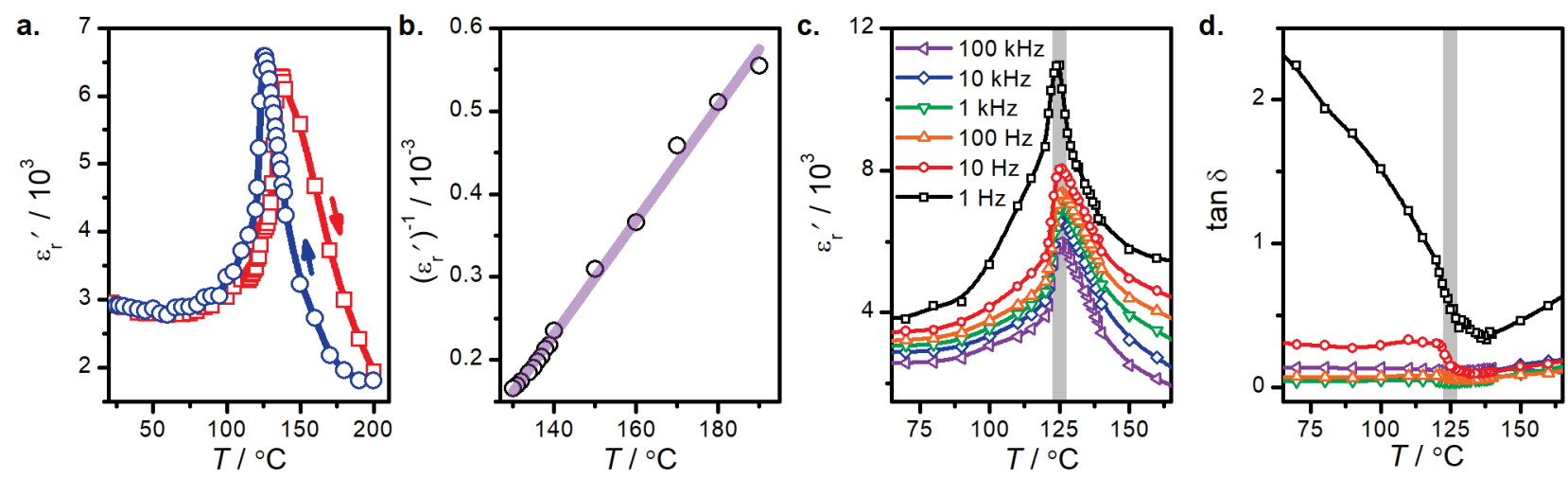

FIG. 5. a. Temperature dependence of the dielectric constant $\left(\varepsilon_{\mathrm{r}}^{\prime}\right)$ for BT-1 at a frequency of $10 \mathrm{kHz}$ showing heating ( $\left.\square\right)$ and cooling (o) cycles. b. Data fit to the Curie-Weiss law. Variation of (c) dielectric constant $\varepsilon_{r}^{\prime}$ and (d) loss tangent (tan $\delta$ ) with temperature at different frequencies for sample BT-1.

\section{REFERENCE}

${ }^{1}$ M. Acosta, N. Novak, V. Rojas, S. Patel, R. Vaish, J. Koruza, G. A. Rossetti, and J. Rodel, Appl. Phys. Rev 4, 041305 (2017).

${ }^{2}$ Z. Zhao, V. Buscaglia, M. Viviani, M. T. Buscaglia, L. Mitoseriu, A. Testino, M. Nygren, M. Johnsson, and P. Nanni, Phys. Rev. B 70, 024107 (2004).

${ }^{3}$ C. Xiao, Z. Chi, W. Zhang, F. Li, S. Feng, C. Q. Jin, X. Wang, X. Deng, and L. Li, J. Phys. Chem. Solids 68, 311-314 (2007).

${ }^{4}$ K. Uchino, E. Sadanaga, and T. Hirose, J. Am. Ceram. Soc. 72, 1555 (1989).

${ }^{5}$ Z. G. Shen, J. F. Chen, H. k. Zou, and J. Yun, J. Colloid Interface Sci. 275, 158-164 (2004)

${ }^{6}$ A. Hirata, Y.and Nitta and M. Kawabata, J.Ceram. Soc. Jpn 102, 1168 (1994).

${ }^{7}$ G. Ciofani, S. S. Danti, Moscato, L. Albertazzi, D. D'Alessandro, D. Dinucci, F. Chiellini, and A. Petrini, M.and Menciassi, Colloids Surf. B: Biointerfaces 76, 535-543 (2010).

${ }^{8}$ J. Li, K. Inukai, A. Tsuruta, Y. Takahashi, and W. Shin, J. Asian. Cerm. Soc. 5, 444-451 (2017).

${ }^{9}$ C. Hai, K. Inukai, Y. Takahashi, N. Izu, T. Akamatsu, T. Itoh, and W. Shin, Mater. Res. Bull. 57, 103-109 (2014).

${ }^{10}$ X. Wang, T. Karaki, K. Koyanagi, and T. Fujii, Jpn. J. Appl. Phys 59, SCCB05 (2020)

${ }^{11}$ L. S. Simon-Seveyrat, A. Hajjaji, Y. Emziane, B. Guiffard, and D. Guyomar, Ceram. Int. 33, 35 (2007)

${ }^{12}$ G. Panomsuwan and H. Manuspiya, J. Appl. Phys. A 124, 10, 1 (2018).

${ }^{13}$ S. K. Lee, T. J. Park, G. J. Choi, K. K. Koo, and S. W. Kim, Mater. Chem. Phys. 82, 742 (2003).

${ }^{14}$ S. G. Kwon, B. H. Park, K. Choi, E. S. Choi, S. Nam, J. W. Kim, and K. J. H., J. Eur. Ceram. Soc. 26, 1401-1404 (2006).

${ }^{15}$ S. S. Tripathy and A. M. Raichur, J. Exp. Nanosci. 6, 127-137 (2011).

${ }^{16}$ J. S. Suk, Q. Xu, N. Kim, J. Hanes, and L. M. Ensign, Adv. Drug. Deliv. Rev. 99, 28-51 (2016).

${ }^{17}$ A. Banerjee, B. Blasiak, E. Pasquier, B. Tomanek, and S. Trudel, RSC Adv. 7, 38125 (2017)

${ }^{18}$ S. Moharana, M. K. Mishra, B. Behera, and R. N. Mahalinga, Polym. Sci. 59, 405-415 (2017).

${ }^{19}$ J. G. Kim, W. P. Tai, K. J. Lee, and W. S. Cho, Ceram. Int. 30, 2223-2227 (2004).

${ }^{20}$ J. Zhu, W. Li, X. Huo, and Y. Zhu, J. Phys. D: Appl. Phys. 48, 355301 (2015).

${ }^{21}$ J. Li, K. Inukai, Y. Takahashi, and W. Shin, J. Asian. Cerm. Soc. 4, 394-402 (2016).

${ }^{22}$ T. Roisnel and J. Rodriguez-Carvajal, Proceedings of the Seventh European Powder Diffraction Conference, Ed. R. Delhez and E.J. Mittenmeijer ,118-123 (2000).

${ }^{23}$ D. M. Smilgies, J. Appl. Cryst. 42, 1030-1034 (2009).
${ }^{24}$ C. A. Schneider, W. S. Rasband, and K. W. Eliceiri, Nat. Methods 9, 671 (2012).

${ }^{25}$ X. H. Wang, X. Y. Deng, H. Zhou, L. T. Li, and I. W. Chen, J. Electroceram. 21, 230 (2008).

${ }^{26}$ M. Taheri, B. Zanca, S. J. Villegas, M. Dolgos, S. Bryant, and S. Trudel, in 2020 Joint Conference of the IEEE International Frequency Control Symposium and International Symposium on Applications of Ferroelectrics (IFCS-ISAF) (2020) pp. 1-4.

${ }^{27}$ Y. Gao, V. V. Shvartsman, A. Elsukova, and D. C. Lupascu, J. Mater. Chem. 22, 17573-17583 (2012).

${ }^{28}$ S. Yoon, S. Baikw, M. G. Kim, N. Shin, and I. Kim, Am. Ceram. Soc. 90, 311-314 (2007).

${ }^{29}$ O. G. Grendal, A. B. Blichfeld, S. L. Skjærvø, W. V. Beek, S. M. Selbach, T. Grande, and M. A. Einarsrud, Crystals 8, 253 (2018).

${ }^{30}$ M. B. Smith, K. Page, T. Siegrist, P. L. Redmond, E. C. Walter, R. Seshadri, L. E. Brus, and S. M. L., J. Am. Chem. Soc. 130, 6955 (2008).

${ }^{31}$ P. M. Diehm, P. Agoston, and K. Albe, Chem. Phys. Chem. 13, 2443 (2012).

${ }^{32}$ S. Tsunekawa, K. Ishikawa, Z. Q. Li, Y. Kawazoe, and A. Kasuya, Phys. Rev. Lett. 85, 3440 (2000).

${ }^{33}$ H. Xu and L. Gao, Mater. Lett. 57, 490-494 (2002).

${ }^{34}$ A. Aala, T. R. Hammad, M. Zawrah, I. K. Battisha, and A. B. Abou Hammad, Acta. Phys. Pol. A. 126 (2014).

${ }^{35}$ J. Stetefeld, S. McKenna, and T. Patel, Biophys Rev. 8, 409 (2016).

${ }^{36}$ S. Bhattacharjee, J. Control. Release. 235, 337-351 (2016).

${ }^{37}$ N. Baskaran, A. Ghule, C. Bhongale, R. Murugan, and H. Chang, J. Appl. Phys. 91, 10038 (2002).

${ }^{38}$ D. Ricinschi, V. Tura, L. Mitoseriu, and M. Okuyama, J. Phys.: Condens. Matter 11, 1601-1613 (1999).

${ }^{39}$ S. Wada, T. Hoshina, K. Takizawa, M. Ohishi, H. Yasuno, H. Kakemoto, T. Tsurumi, C. Moriyoshi, and Y. Kuroiwa, J Korean Phys Soc 51, 2, 878 (2007). 
TABLE OF CONTENT GRAPHIC

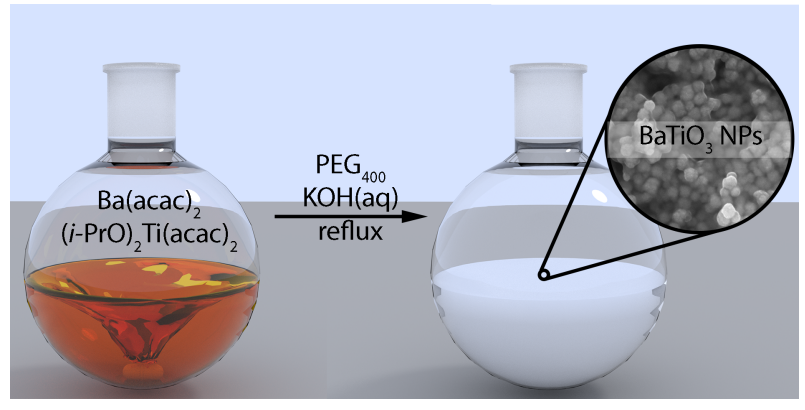

Water-dispersible $\mathrm{BaTiO}_{3}$ nanoparticles coated with poly(ethyleneglycol) can be synthesized via an easy, one-pot synthesis. These nanoparticles maintain their ferroelectric properties down to $60 \mathrm{~nm}$. 


\title{
Electronic Supplementary Information. Water-dispersible and ferroelectric PEGylated barium titanate nanoparticles
}

\author{
M. Taheri, ${ }^{* a, b, c}$ B. Zanca, ${ }^{a}$ M. Dolgos,${ }^{a}$ S. Bryant,${ }^{c}$ and S. Trudel ${ }^{* * a, b}$ \\ ${ }^{a}$ Department of Chemistry, University of Calgary, 2500 University Dr NW, Calgary, AB, Canada. \\ ${ }^{b}$ Institute for Quantum Science and Technology, University of Calgary, 2500 University Dr NW, Calgary, AB, Canada. \\ ${ }^{c}$ Department of Chemical and Petroleum Engineering, University of Calgary, 2500 University Dr NW, Calgary, AB, Canada. \\ ^E-mail: maryam.taheri2@ucalgary.ca

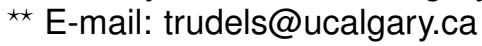




\section{S1. SUPPLEMENTARY METHODS}

\section{A. Materials}

High-purity barium(II) acetylacetonate hydrate $\left(\mathrm{Ba}(\mathrm{acac})_{2} \cdot \mathrm{xH}_{2} \mathrm{O}\right)$ and titanium diisopropoxide bis(acetylacetonate) $((\mathrm{O}-i$ $\mathrm{Pr})_{2} \mathrm{Ti}(\mathrm{acac})_{2}, 75 \mathrm{wt} \%$ in isopropanol), poly(ethyleneglycol) $\left.\left(\mathrm{HO}\left(\mathrm{CH}_{2} \mathrm{CH}_{2} \mathrm{O}\right)_{n} \mathrm{H}\right) ; \mathrm{PEG}_{400}: M_{\mathrm{W}}=400\right)$ and potassium hydroxide $(\mathrm{KOH}, 85 \%)$ were purchased from Sigma Aldrich. Ethanol, glacial acetic acid $(99.7 \%)$ and formic acid $(98 \%)$ were used for nanoparticles' washing procedure. All chemicals and solvents were used as-received without any further purification. Highpurity water (resistivity of $18 \mathrm{M} \Omega \cdot \mathrm{cm}$ ) was used in all experiments.

\section{B. Nanoparticle Synthesis}

Synthesis of BT-0. We dissolved $\mathrm{Ba}(\mathrm{acac})_{2} \cdot \mathrm{xH}_{2} \mathrm{O}(355 \mathrm{mg}, 1 \mathrm{mmol})$ and $(\mathrm{O}-i \text {-Pr })_{2} \mathrm{Ti}(\mathrm{acac})_{2}(273 \mathrm{mg}, 1 \mathrm{mmol}) \mathrm{precursors}$ in a round-bottom flask under nitrogen atmosphere, and let the solution stir for $30 \mathrm{~min}$. We then added aqueous $\mathrm{KOH}(6 \mathrm{~mL}, 1.5$ $\mathrm{M})$ to the mixture. Immediately after, we increased the reaction temperature to reflux $\left(\mathrm{ca} .100 \pm 5^{\circ} \mathrm{C}\right)$, and allowed the reaction to reflux for $2 \mathrm{hrs}$.

Synthesis of BT-2. We dissolved $\mathrm{Ba}(\mathrm{acac})_{2} \cdot \mathrm{xH}_{2} \mathrm{O}(710 \mathrm{mg}, 2 \mathrm{mmol})$ and $(\mathrm{O}-i \text {-Pr })_{2} \mathrm{Ti}(\mathrm{acac})_{2}(273 \mathrm{mg}, 1 \mathrm{mmol}) \mathrm{precursors}$ in $3 \mathrm{~mL}_{\text {of }} \mathrm{PEG}_{400}$ in a round-bottom flask under nitrogen atmosphere, and let the solution stir for 30 min. We then added aqueous $\mathrm{KOH}(6 \mathrm{~mL}, 1.5 \mathrm{M})$ to the mixture. Immediately after, we increased the reaction temperature to reflux $\left(\mathrm{ca}\right.$. $\left.100 \pm 5^{\circ} \mathrm{C}\right)$, and allowed the reaction to reflux for $2 \mathrm{hrs}$.

Synthesis of BT-3. We dissolved $\mathrm{Ba}(\mathrm{acac})_{2} \cdot \mathrm{xH}_{2} \mathrm{O}(355 \mathrm{mg}, 1 \mathrm{mmol})$ and $(\mathrm{O}-i \text {-Pr })_{2} \mathrm{Ti}(\mathrm{acac})_{2}(273 \mathrm{mg}, 1 \mathrm{mmol}) \mathrm{precursors}$ in $6 \mathrm{~mL}$ of $\mathrm{PEG}_{400}$ in a round-bottom flask under nitrogen atmosphere, and let the solution stir for 30 min. We then added aqueous $\mathrm{KOH}(6 \mathrm{~mL}, 1.5 \mathrm{M})$ to the mixture. Immediately after, we increased the reaction temperature to reflux $\left(\mathrm{ca}\right.$. $\left.100 \pm 5{ }^{\circ} \mathrm{C}\right)$, and allowed the reaction to reflux for $2 \mathrm{hrs}$.

Synthesis of BT-4. We dissolved $\mathrm{Ba}(\mathrm{acac})_{2} \cdot \mathrm{xH}_{2} \mathrm{O}(355 \mathrm{mg}, 1 \mathrm{mmol})$ and $(\mathrm{O}-i \text {-Pr })_{2} \mathrm{Ti}(\mathrm{acac})_{2}(273 \mathrm{mg}, 1 \mathrm{mmol}) \mathrm{precursors}$ in $3 \mathrm{~mL}_{\text {of }} \mathrm{PEG}_{400}$ in a round-bottom flask under nitrogen atmosphere, and let the solution stir for 30 min. We then added aqueous $\mathrm{KOH}(6 \mathrm{~mL}, 1.6 \mathrm{M})$ to the mixture. Immediately after, we increased the reaction temperature to reflux $\left(\mathrm{ca}\right.$. $\left.100 \pm 5^{\circ} \mathrm{C}\right)$, and allowed the reaction to reflux for $2 \mathrm{hrs}$.

Synthesis of BT-5. We dissolved $\mathrm{Ba}(\mathrm{acac})_{2} \cdot \mathrm{xH}_{2} \mathrm{O}(355 \mathrm{mg}, 1 \mathrm{mmol})$ and $(\mathrm{O}-i \text {-Pr })_{2} \mathrm{Ti}(\mathrm{acac})_{2}(273 \mathrm{mg}, 1 \mathrm{mmol}) \mathrm{precursors}$ in $3 \mathrm{~mL}$ of $\mathrm{PEG}_{400}$ in a round-bottom flask under nitrogen atmosphere, and let the solution stir for 30 min. We then added aqueous $\mathrm{KOH}(6 \mathrm{~mL}, 1.7 \mathrm{M})$ to the mixture. Immediately after, we increased the reaction temperature to reflux $\left(\mathrm{ca}\right.$. $\left.100 \pm 5{ }^{\circ} \mathrm{C}\right)$, and allowed the reaction to reflux for $2 \mathrm{hrs}$.

For all syntheses, the color of solution gradually changed from orange/brown to white. After 2 hrs of reflux, we added 6 mL of distilled water to the mixture and maintained it at $100 \pm 5^{\circ} \mathrm{C}$ for an additional $2 \mathrm{hrs}$. We then opened the system to air and let the reaction cool down to room temperature. white precipitates were collected by washing and centrifugation (6000 rpm for 10 min) two times with ethanol, followed by formic acid (1 M). Carbonate impurities were removed by washing the product with diluted $(0.5 \mathrm{w} / \mathrm{w} \%)$ acetic acid. Finally, the nanoparticles were dried at $60{ }^{\circ} \mathrm{C}$ in a vacuum oven overnight. 


\section{S2. SUPPLEMENTARY DATA}

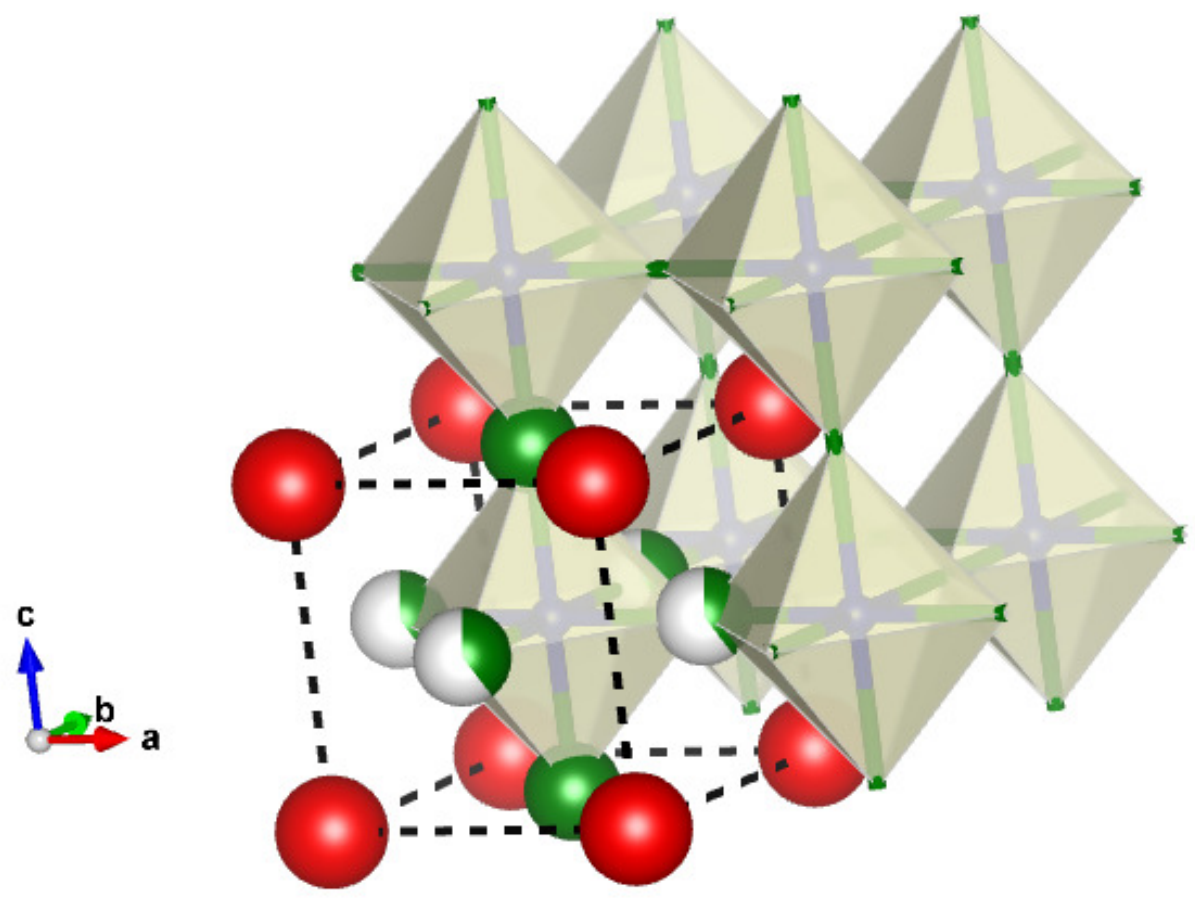

FIG. S1. The tetragonal crystal structure of $\mathrm{BaTiO}_{3}$ nanopowders. $\mathrm{Ti}^{4+}$ ions (blue atoms) with ionic radius of $0.605 \AA$ are surrounded by six oxygen ions (green atoms) and create the $\mathrm{TiO}_{6}$ octahedral, while $\mathrm{Ba}^{2+}$ ions with ionic radius of $1.61 \AA$ and coordination number of 12 are located at the corner of unit cell cube (shown with dashed line). Solid green balls are $\mathrm{O}_{1}$ and green/white balls are labeled as $\mathrm{O}_{2}$ atoms.

To determine crystallite size of particles, the (110) Bragg peak at was fit as a Lorentzian peak, and crystallite size ( $\left.D_{\mathrm{XRD}}\right)$ was calculated using the Scherrer equation: ${ }^{23}$

$$
D_{\mathrm{XRD}}=\frac{K \lambda}{\beta \cos \theta}
$$

where $\lambda$ is the incident wavelength, $K$ is the shape factor ( $=0.94$ for spherical crystallites), $\beta$ is the instrument-corrected line broadening of the sample at half the maximum intensity (FWHM), in radians, which is estimated through equation:

$$
\beta=\beta_{\text {observed }}-\beta_{\text {ref }}
$$

Here, $\beta_{\text {observed }}$ is the measured line broadening at half the maximum intensity for the nanoparticle sample (see Fig. S3), while $\beta_{\text {ref }}$ and is the measured line broadening at half the maximum intensity for microcrystalline $\mathrm{BaTiO}_{3}$, taken to be representative

\begin{tabular}{|c|c|c|c|}
\hline Atom & Multiplicity & Wyckoff & Coordinates \\
\hline $\mathrm{Ba}$ & 1 & $1 \mathrm{a}$ & $(0,0,0)$ \\
\hline $\mathrm{Ti}$ & 1 & $1 b$ & $(0.5,0.5,0.5)$ \\
\hline $\mathrm{O} 1$ & 1 & $1 b$ & $(0.5,0.5,0)$ \\
\hline $\mathrm{O} 2$ & 2 & $2 \mathrm{c}$ & $(0.5,0,0.5)$ \\
\hline
\end{tabular}
of instrumental broadening.

TABLE S1. Multiplicity, Wyckoff positions and an atomic positions in $\mathrm{BaTiO}_{3}$ structure with tetragonal structure (space group of $P 4 / m m m$ ). 

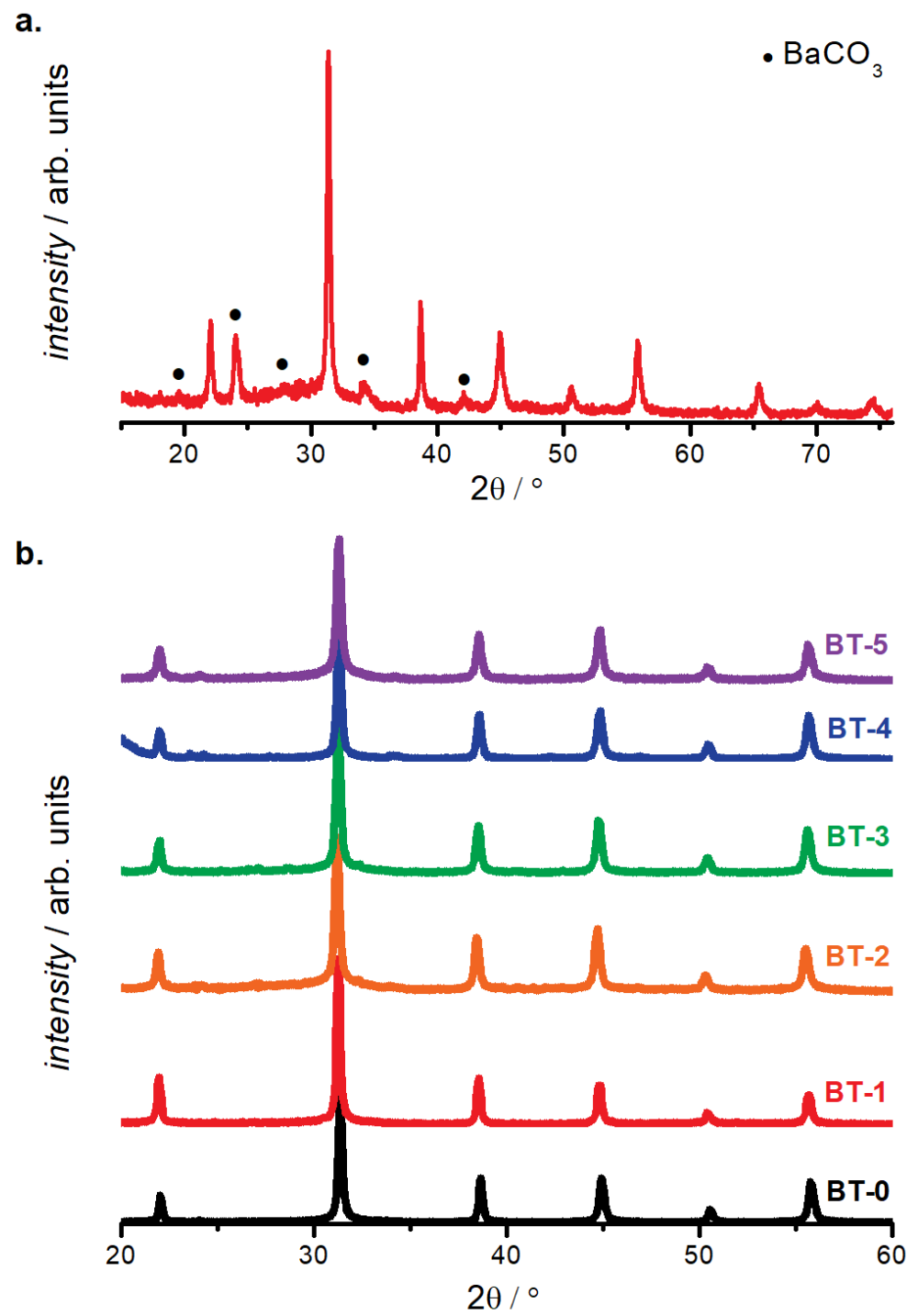

FIG. S2. a. PXRD pattern of BT-1 before washing with dilute acetic acid. Circles correspond to Bragg peaks arising from $\mathrm{BaCO}_{3}$ impurity. These impurities were removed after washing the powders with diluted acetic acid $(0.5 \mathrm{wt} \%)$. b. PXRD patterns of all $\mathrm{BaTiO}_{3}$ samples after washing with dilute acetic acid. All peaks are assigned to the pure $\mathrm{BaTiO}_{3}$ phase.

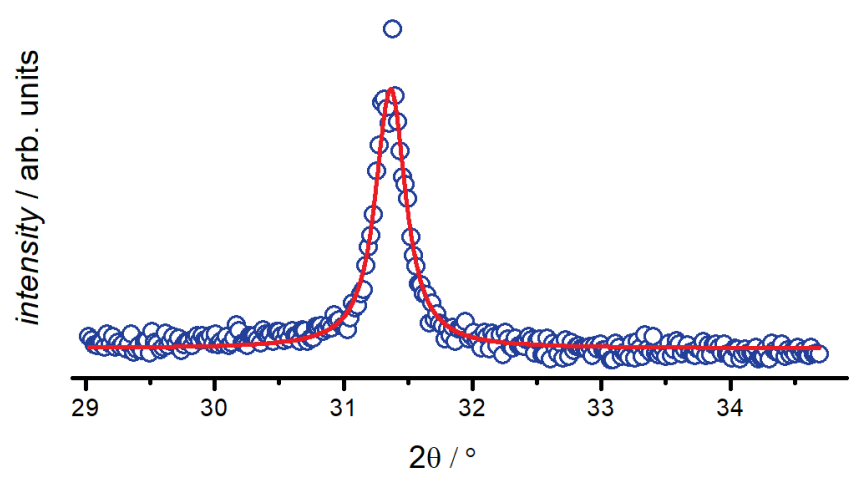

FIG. S3. Lorentzian fit of the (110) Bragg reflection for sample BT-1. 

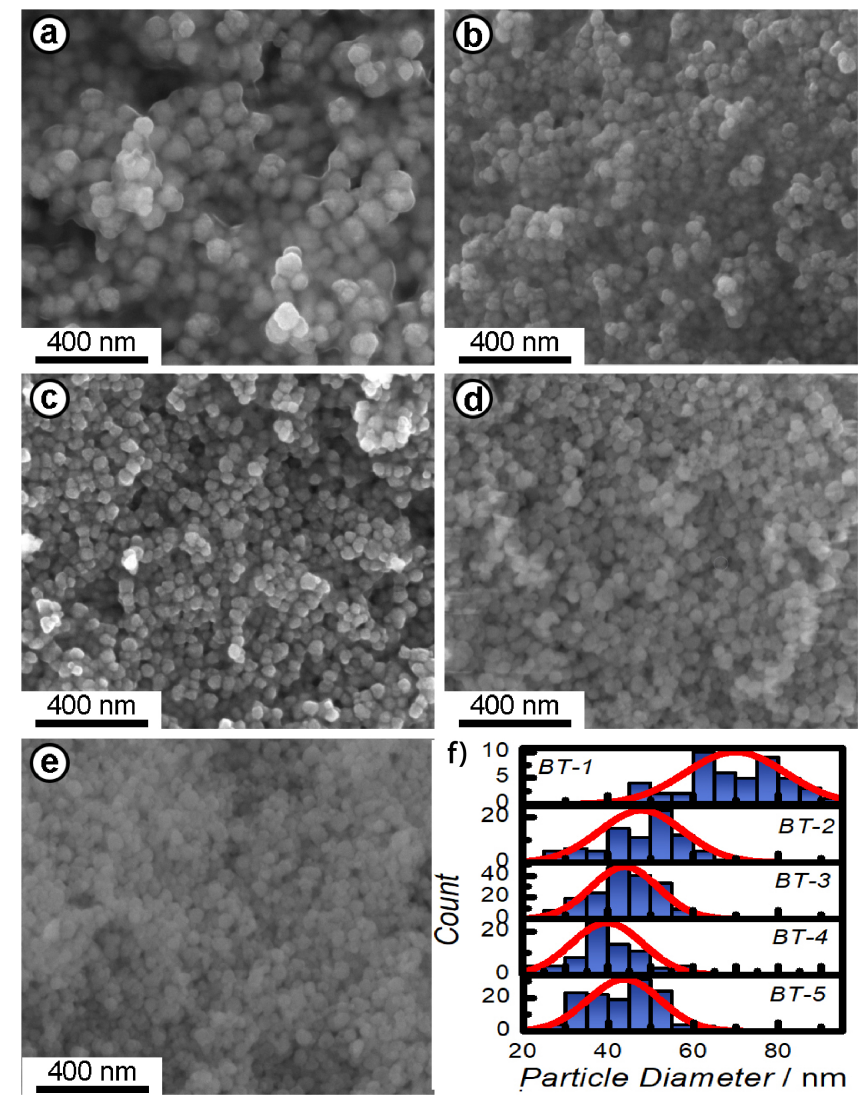

FIG. S4. SEM micrographs of PEGylated-BaTiO 3 nanopowders at room temperature for samples a) BT-1, b) BT-2 and c) BT-3, d) BT-4, e) BT-5 and f) corresponding histograms. 


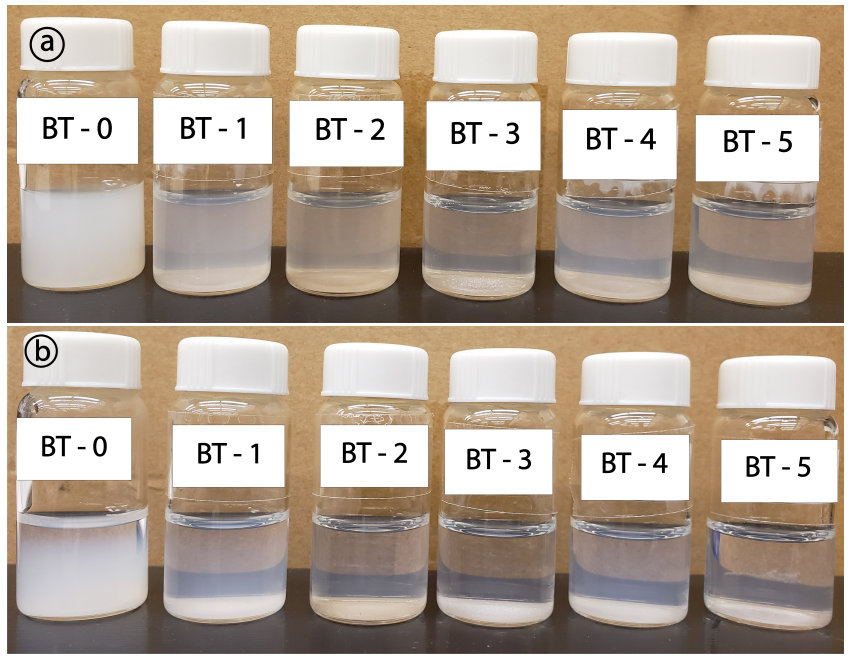

FIG. S5. Stability test of $100 \mathrm{ppm}$ nanoparticles in DI water $(\mathrm{pH} \approx 7)$ at room temperature: a) Fresh solutions, b) after 24 hrs. 